\title{
Measurements of Gas Sorption from Seawater and the Influence of Gas Release on Open-Cycle Ocean Thermal Energy Conversion (OC-OTEC) System Performance
}

Terry R. Penney

Jay A. Althof

June 1985

Prepared for

INTERSOL ' 85 - Biennial Conference of the International Solar Energy Society

Montreal, Quebec, Canada

23-29 June 1985

Prepared under Task No. 4006.21

FTP No. 523

Solar Energy Research Institute

A Division of Midwest Research Institute

1617 Cole Boulevard

Golden, Colorado 80401

Prepared for the

U.S. Department of Energy

Contract No. DE-AC02-83CH10093 


\section{NOTICE}

This report was prepared as an account of work sponsored by the United States Government. Neither the United States nor the United States Department of Energy, nor any of their employees, nor any of their contractors, subcontractors, or their employees, makes any warranty, expressed or implied, or assumes any legal liability or responsibility for the accuracy, completeness or usefulness of any information, apparatus, product or process disclosed, or represents that its use would not infringe privately owned rights.

Printed in the United States of America

Available from:

National Technical Information Service

U.S. Department of Commerce

5285 Port Royal Road

Springfield, VA 22161

Price: Microfiche $\mathrm{A} 01$

Printed Copy A02

Codes are used for pricing all publications. The code is determined by the number of pages in the publication. Information pertaining to the pricing codes can be found in the current issue of the following publications, which are generally available in most libraries: Energy Research Abstracts, (ERA); Government Reports Announcements and Index (GRA and I); Scientific and Technical Abstract Reports (STAR); and publication, NTIS-PR-360 available from NTIS at the above address. 


\title{
MEASUREMENTS OF GAS SORPTION FROM SEAWATER AND THE INFLUENCE OF GAS RELEASE ON OPEN-CYCLE OCEAN THERMAL ENERGY CONVERSION (OC-OTEC) SYSTEM PERFORMANCE
}

\author{
Terry R. Penney, Jay A. Althof \\ Solar Energy Research Institute, 1617 Cole Boulevard \\ Golden, Colorado 80401, USA
}

\begin{abstract}
The technical community has questioned the validity and cost-effectiveness of opencycle ocean thermal energy conversion (OC-OTEC) systems because of the unknown effect of noncondensable gas on heat exchanger performance and the power needed to run vacuum equipment to remove this gas. To date, studies of seawater gas desorption have not been prototypical for system level analysis. This study gives preliminary gas desorption data on a vertical spout, direct contact evaporator and multiple condenser geometries. Results indicate that dissolved gas can be substantially removed before the seawater enters the heat exchange process, reducing the uncertainty and effect of inert gas on heat exchanger performance.
\end{abstract}

\section{KEYWORDS}

OC-OTEC; gas desorption; deaeration; OTEC systems; NELH; seawater.

\section{BACKGROUND OF THE PROBLEM}

With open-cycle OTEC warm seawater enters an evacuated vessel with pressure low enough to cause flash boiling. Cold seawater, acting as a condenser, comes from a depth of nominally $1000 \mathrm{~m}$ and mixes with the steam. A large, low pressure turbine between the evaporator and condenser extracts work from this thermal energy difference. A key issue open-cycle system researchers face is to quantify the amount of power required to maintain the levels of vacuum needed to maintain steady-state flash boiling and to condense seawater.

Noncondensable gas comes from system leaks and evolves from the seawater feedstreams being nearly saturated with nitrogen and oxygen at atmospheric pressure on the warm side and nearly saturated with nitrogen but only $15 \%$ saturated with oxygen on the cold side.

Conservative calculations show that even if all the dissolved gas in seawater comes out, the parasitic power load (gross-net) for the vacuum exhaust system is only $10 \%$. However, noncondensable gas decreases condenser performance by reducing the steam partial pressure and, thus, the driving potential for mass transfer [1]. Several studies have attempted to quantify barometric leg deaeration and packed column deaeration as m ethods to remove the noncondensable gases before the heat exchange process $[2,3]$.

Until recently, deaeration results were only available for freshwater and, to a very limited degree, seawater at conditions (generally higher temperatures) not appropriate to OC-OTEC analysis. In a companion paper at this conference, Krock and Zapka [4] 
discuss their results on gas evolution and deaeration prior to any heat exchange process. This paper complements that work and discusses experimental results of gas evolution rates for particular seawater evaporator and condenser geometries and the effect on system performance.

\section{EXPERIMENTAL SET-UP}

The experiments were carried out at the Natural Energy Laboratory of Hawaii (NELH) located at Keahole Point on the big island of Hawaii. A schematic of the test system located at NELH is shown in Fig. 1. The system uses separate evaporator and condenser tanks, which have observation ports, drain and inlet lines, and temperature and pressure measurement points and are connected by a short, 30-cm-diameter PVC "gooseneck." The units are mounted on the top deck of the coldwater header tank tower at $\mathrm{NELH}$, which is approximately $11 \mathrm{~m}$ above mean sea level [5].

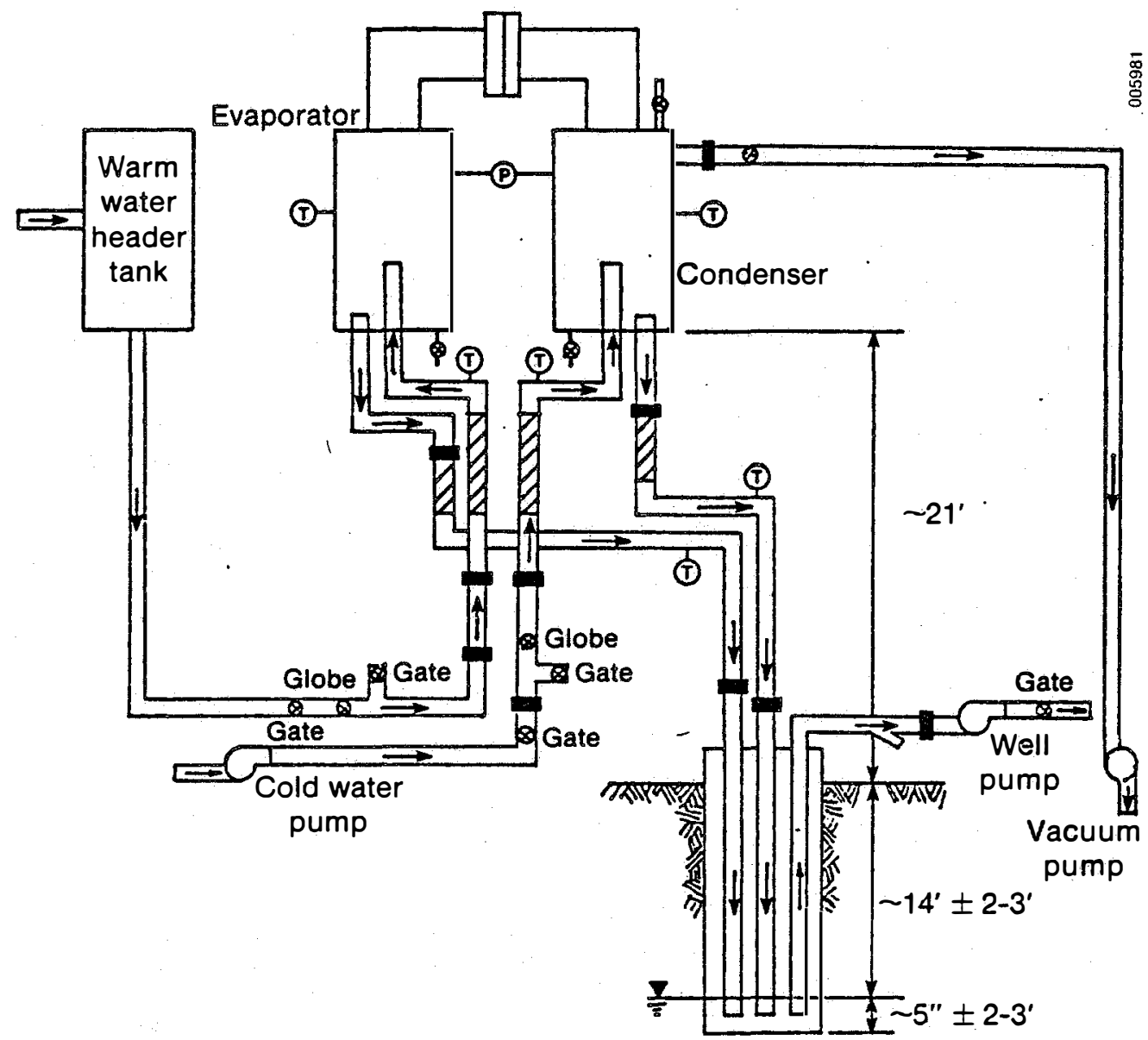

Fig. 1. Schematic of OC-OTEC experiment

Experimentally, a $1-\mathrm{cm}^{3}$ sample of seawater was titrated into a glass manometer tube and filmed several times in a vacuum atmosphere produced by a mercury piston activator. The released gases were then pressurized to atmospheric pressure and the volume measured in the graduated manometer tube.

Typically, preprocessed samples of warm and cold seawater were obtained from the header tanks, and postprocess samples were removed via the drains of the evaporator and condenser modules. The majority of the samples were not removed under experi- 
mental operating vacuum conditions but rather at atmospheric pressure after quickly venting the test chamber. A limited number of further samples were taken using a sampling device operating under system vacuum conditions.

\section{RESULTS}

Table 1 summarizes the dissolved gas measurements taken on 12-16 September 1983 . In addition, measurements taken on 18-22 February 1985 are included. The background levels of total dissolved gas are consistent with Krock's [6] values taken of KAHE Point in 1981. However, there is some discrepancy between the data taken in September 1983 and February 1985, due in part to the different sampling techniques used. A recent study on noncondensable gas exchange [4] indicates that the majority of the inert gases contained in seawater can be removed before the heat exchanger processes using passive deaeration. These results indicate that the data taken during February 1985 may be closer to the proper values, reemphasizing that sampling techniques are important to the deaeration process results.

Table 1. Average Dissolved Gas Measurements

\begin{tabular}{lcc}
\hline & $\begin{array}{c}\text { Gas Content } \\
\text { (\% Volume) }\end{array}$ & $\begin{array}{c}\text { Percentage } \\
\text { Liberated }\end{array}$ \\
\hline Warm water $\left(26.7^{\circ} \mathrm{C}\right)$ & 1.6 & N.A. \\
Cold seawater $\left(9^{\circ} \mathrm{C}\right)$ & 1.7 & N.A. \\
Evaporator exit & 0.5 & 64 \\
Evaporator exit* & 0.3 & 83 \\
Condenser exit & 0.3 & 79 \\
Condenser exit* & 0.3 & 82 \\
\hline
\end{tabular}

*Data taken with vacuum sample device.

The warm seawater (nominally $26^{\circ} \mathrm{C}$ ) is taken from a depth of $8.2 \mathrm{~m}$, several hundred meters offshore and is pumped to the header tanks on a separate $6.5-\mathrm{m}$ tower. The OC-OTEC test facility taps the fluid after the header tank at ground level. The cold seawater (nominally $9^{\circ} \mathrm{C}$ ) is pumped to a header tank also located at $6 \mathrm{~m}$ above ground level. The OC-OTEC test facility taps the cold seawater at ground level before it reaches this header tank.

The instrumentation for this project included water flow meters, resistance temperature detectors (RTD) and pressure transducers to map the performance of the direct contact heat exchangers located inside the tank. A Seaton-Wilson AD-4000 Series "Aire-Ometer" measured the dissolved gas content in the seawater.

The release of inert gases from seawater under vacuum conditions occurs because of some combination of four mechanisms: microbubbles, molecular diffusion, homogeneous nucleation, and heterogeneous nucleation [7]. The volume of gas contained in microbubbles is very small compared with the dissolved gas content; however, they will probably act as nucleation sites. We have yet to find the diffusion coefficient for dissolved gases in seawater in the literature. However, a study by Liu [8] indicates that the diffusion coefficient of dissolved gases in saline water may be about twice that for freshwater. Using this value, we can estimate the contribution of diffusion for gas release. For reasonable flow conditions this value is only about $20 \%-40 \%$ of the total gas released. This leaves the nucleation mechanisms. Homogeneous nucleation is what occurs within the bulk fluid (i.e., microbubbles, plankton, cavitation, etc.), and heterogeneous nucleation is initiated from defects along the pipe walls or other objects in the flow path. Visual observation of numerous bubbles in the inlet process flow stream suggests that nucleation (mostly homogeneous) may be the primary mechanism in the seawater desorption process. 
Recent data by Krock [4] indicate that dissolved gas is released from the flow streams as the water passes up the barometric legs approaching the heat exchangers. Figure 2 shows the fraction of equilibrium data for warm and cold seawater in addition to freshwater as a function of deaeration pressure. The included symbols indicate the fraction of equilibrium as measured at the outlet of the heat exchangers. This figure indicates that the warm seawater releases gas at a much higher rate (factor of 2) than either the cold seawater or freshwater. This may be because of, at least in part, the abundance of homogeneous nucleation sites available in the warm seawater. This difference also indicates that it may be possible to increase the deaeration of the cold seawater by using some external nucleation seeding device. The measured gas release values from the heat exchangers compare quite favorably with the extrapolated section of the deaerator curves. This close comparison indicates that the effect of passive predeaeration can be analyzed using deaeration curves.

An overall systems analysis was performed using the thermodynamic systems model developed by Parsons [9] and the cost algorithms developed by Block [10]. Figure 3 shows the effect of passive deaeration on the net-to-gross-power ratio of an OC-OTEC system. An increase of about $6 \%$ in the net to gross power ratio can be obtained with about $99 \%$ predeaeration. The increase in this ratio comes from two primary sources. From Fig. 2 we found that about $80 \%$ of the dissolved gas would be released in the evaporator and condenser if the seawater is not predeaerated. This would require that the entire inert gas flow would have to be compressed from the condenser pressure to atmospheric pressure. With predeaeration the majority of the inert gas will be compressed to atmospheric pressure from pressures significantly above the condenser pressure resulting in an increase available system power.

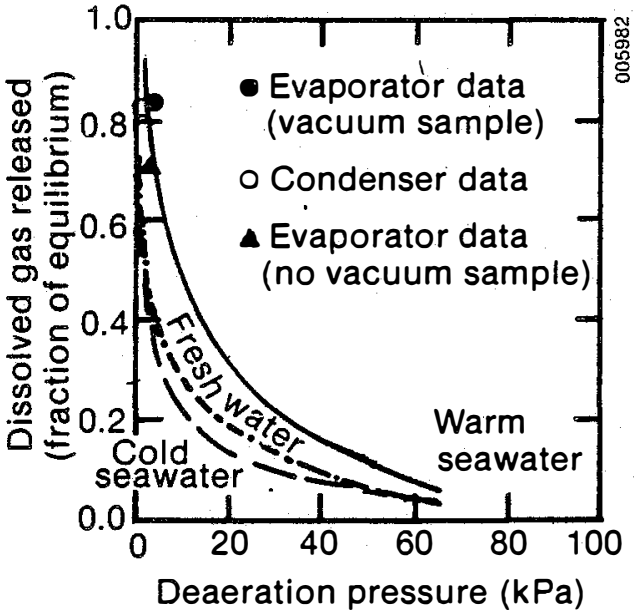

Fig. 2. Experimentally measured deaeration

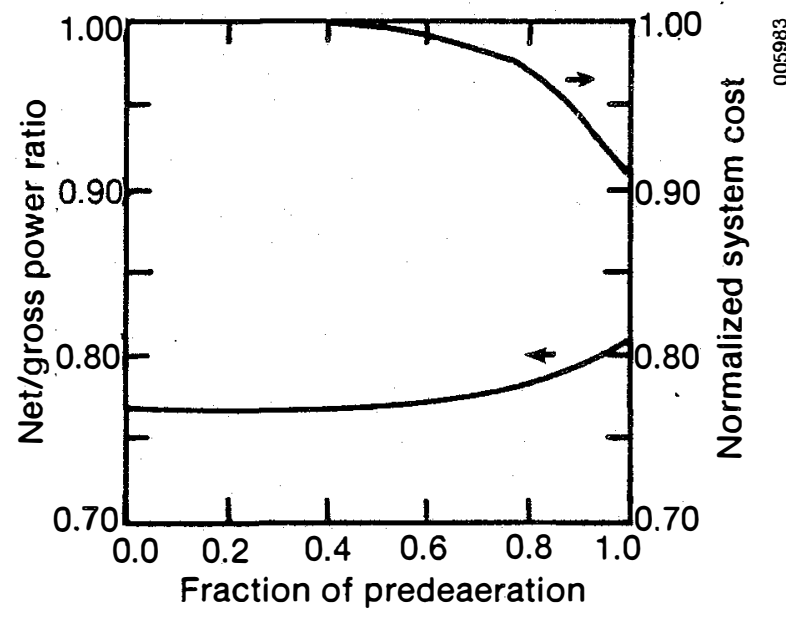

Fig. 3. Effect of predeaeration on OC-OTEC system performance

In addition, the performance of the direct-contact condensers is reduced significantly because of the presence of inert gases. In a report on direct-contact condensers Bharathan [1] showed that about a $30 \%$ reduction in steam condensed occurred when the inlet seawater was not predeaerated. This additional mass flow must then be compressed to atmospheric pressure from the condenser pressure requiring additional power.

Figure 3 also shows the effect of predeaeration on system cost. This figure shows that predeaeration of $99 \%$ yields a reduction in system cost of about $10 \%$. It may be possible to improve the cost savings by further systems analysis optimization. 


\section{CONCLUSIONS}

Preliminary data of gas desorption in seawater indicate that the bulk of the dissolved gases will have evolved by the completion of the evaporation or condensation process. Conservative calculations show that even if all the dissolved gas in seawater comes out, the parasitic power load for the vacuum exhaust system is only about $10 \%$ of the gross power output of the open-cycle OTEC system. However, the reduction in condenser performance and the increase in compressor power makes about a $10 \%$ difference in system cost without passive predeaeration, a conclusion which contradicts previous studies $[2,3]$ on predearation.

The relative importance between homogeneous and heterogeneous nucleation is not presently known. There is a possibility that heterogeneous nucleation will decrease after prolonged operation of the process stream because of the re-solution of the gases initially trapped in the pipe wall defects. However, there are alternatives for introducing heterogeneous nucleation sites into the process path (i.e., injection of small gas bubbles) to increase the amount of gas released, which gives further promise to the cost viability of OC-OTEC. The variation in measured gas release with and without vacuum sampling devices emphasizes the importance of not only measurement techniques but also system process path.

\section{ACKNOWLEDGMENT}

We wish to gratefully acknowledge Mr. Peter Ritzcoven, Program manager in the Ocean Energy Program for the Department of Energy, who sponsored this research.

\section{REFERENCES}

1. D. J. Bharathan, J. Althof, and B. Parsons, Direct-contact condensers for opencycle ocean thermal energy conversion (OTEC) applications. Draft report RR-252-2472, Solar Energy Research Institute, Golden, Colorado (1985).

2. A. Golshani, and F. C. Chen, Ocean thermal energy conversion gas desorption studies. ORNL/TM-7438/V, Oak Ridge National Laboratory, Oak Ridge, Tennessee, (1981).

3. $\quad 100 \mathrm{MW}$ OTEC alternate power systems. Final report by Westinghouse Electric Corporation to U.S. DOE under contract EG-77-C-05-1473, Vol. 1 (1979).

4. H. Krock, and M. Zapka, Open-cycle OTEC noncondensible gas exchange characteristics. To be presented at the Intersol 85 Conference, Montreal, Canada, (June 1985).

5. J. Larson-Basse, Open-cycle ocean thermal energy conversion experiment. Preliminary report to the Solar Energy Research Institute, Golden, Colorado (1983)。

6. H. Krock, Gas analyses of water samples for OTEC program. Technical report No. 5 l, J.K.K. Look Laboratory (1981).

7. A. T. Wassel, D. C. Bugby, and A. F. Mills, Bubble nucleation and growth in opencycle ocean thermal energy conversion subsystems. SAI-083-83R-002, Science Applications, Inc. (1982).

8. J. L. Liu, The determination of the rates of diffusion of dissolved oxygen in saline waters. Masters Thesis, the Graduate School University of Maine, Orono (1970).

9. B. J. Parsons, J. Althof, and D. Bharathan, Thermodynamic systems analysis of open-cycle ocean thermal energy conversion (OTEC). TR-252-2234, Solar Energy Research Institute, Golden, Colorado (1984).

10. D. L. Block, et al., Thermoeconomic optimization of OC-OTEC electricity and water production plants. Report FSEC-CR-108-84 and TM-977, Florida Solar Energy Center and Creare R\&D, Inc. (1984). 